\title{
Комплексная терапия
}

\section{острых респираторных заболеваний}

\section{H.В. Орлова, ORCID: 0000-0002-4293-3285, e-mail: vrach315@yandex.ru}

Российский национальный исследовательский медицинский университет имени Н.И. Пирогова; 117997, Россия, Москва, ул. Островитянова, д. 1

\section{Резюме}

Острые респираторные заболевания (ОР3) являются распространенной патологией. Несвоевременная диагностика и лечение, наличие сопутствующих заболеваний, пожилой возраст и возраст детей до 1 года, беременность могут утяжелять течение и приводить к развитию осложнений и летальному исходу. Согласно рекомендациям IDSA, эффективной профилактикой осложнений и летальных исходов гриппа является вакцинация. В первую очередь вакцинации подлежат граждане из групп риска тяжелого течения заболевания. В случаях подозрения на грипп рекомендовано проведение молекулярной диагностики. В то же время лечение при подозрении на грипп необходимо назначать безотлагательно, не дожидаясь лабораторного подтверждения диагноза. На первом месте в терапии острых респираторных вирусных инфекций должно быть этиотропное лечение, направленное на подавление репликации вирусов. Бактериальные возбудители могут являться первичной причиной респираторных заболеваний или осложнять вирусные заболевания. При наличии бактериального возбудителя назначаются антибактериальные препараты. Симптомы ОРЗ ухудшают качество жизни пациентов. Комплексное лечение респираторных заболеваний включает назначение симптоматической терапии: жаропонижающих, противокашлевых, при ринорее - сосудосуживающих препаратов. Кашель является наиболее распространенным респираторным симптомом. При различных заболеваниях кашель имеет свои особенности, что позволяет провести дифференциальную диагностику. Американской коллегией специалистов торакальной медицины предложены схемы дифференциального поиска острого и хронического кашля, позволяющие рационально провести диагностику заболеваний. Применение противокашлевых препаратов имеет свои особенности: при сухом кашле назначаются препараты, подавляющие кашель, при продуктивном кашле - препараты, направленные на облегчение эвакуации мокроты. Одним из препаратов, обладающих отхаркивающим, муколитическим и спазмолитическим действием, является сироп Геделикс на основе плюща.

Ключевые слова: острые респираторные заболевания, рекомендации IDSA, лечение, кашель, плющ

Для цитирования: Орлова Н.В. Комплексная терапия острых респираторных заболеваний. Медицинский совет. 2019;(15):91-97. doi: 10.21518/2079-701X-2019-15-91-97.

Конфликт интересов: автор заявляет об отсутствии конфликта интересов.

\section{Complex therapy of acute respiratory diseases}

Natal'ya V. Orlova, ORCID: 0000-0002-4293-3285, e-mail: vrach315@yandex.ru

Pirogov Russian National Research Medical University;: 1, Ostrovityanova st., Moscow 117997, Russia

\begin{abstract}
Acute respiratory disease (ARD) is a common pathology. Untimely diagnosis and treatment, co-morbidities, old age and children under 1 year of age, pregnancy can increase the severity of the condition and lead to complications and death. According to IDSA recommendations, vaccination is an effective way to prevent complications and fatal influenza cases. Vaccination is primarily for people at risk of serious illness. In cases of suspected influenza, molecular diagnostics is recommended. At the same time, treatment of suspected influenza should be prescribed immediately, without waiting for laboratory confirmation of the diagnosis. Etiotropic treatment aimed at suppressing virus replication should be the first priority in the treatment of acute respiratory viral infections. Bacterial agents may be the primary cause of respiratory diseases or may complicate viral diseases. In the presence of a bacterial pathogen, antibacterial agents are prescribed. ARD symptoms worsen the quality of life of patients. Complex treatment of respiratory diseases includes the prescription of symptomatic therapy: antipyretics, antitussives, vasoconstrictor drugs in rhinorrhea. Cough is the most common respiratory symptom. In various diseases, cough has its own peculiarities, which allows you to carry out differential diagnosis. The American Thoracic Society has proposed schemes of differential search for acute and chronic coughs, which allow rational diagnosis of diseases. The use of antitussive drugs has its own peculiarities: when the cough is non-productive, drugs are prescribed to suppress cough, when the cough is productive drugs are aimed at facilitating the evacuation of sputum. One of the preparations possessing expectorant, mucolytic and antispasmodic action, is Hedelix syrup on the basis of ivy.
\end{abstract}

Keywords: acute respiratory diseases, IDSA recommendations, treatment, cough, ivy

For citation: Orlova N.V. Complex therapy of acute respiratory diseases. Meditsinskiy sovet = Medical Council. 2019;(15):91-97. (In Russ.) doi: 10.21518/2079-701X-2019-15-91-97.

Conflict of interest: The authors declare no conflict of interest. 


\section{ВВЕДЕНИЕ}

Острые респираторные заболевания (ОРЗ), в т. ч. грипп, лидируют в структуре всей инфекционной заболеваемости, составляя до 1 млрд человек в год, и обусловливают высокую потерю временной трудоспособности, особенно в период эпидемий. При подведении итогов эпидемического подъема заболеваемости гриппом в 2018-2019 гг. Федеральной службой по надзору в сфере защиты прав потребителей и благополучия человека было отмечено, что широкий охват населения вакцинацией против гриппа, который составил 49\%, способствовал сдерживанию развития эпидемии. В новых рекомендацияx IDSA (Infectious Diseases Society of America, IDSA), опубликованных на Clinical Infectious Diseases, также отмечается, что вакцинация является одним из основных методов профилактики гриппа.

Госпитализация и летальность при ОРЗ связаны с развитием тяжелой острой респираторной инфекции (ТОРИ), а также утяжелением течения сопутствующей соматической патологии [1].

\section{ЭТИОЛОГИЯ И ДИАГНОСТИКА}

При ОРЗ происходит поражение слизистой верхних дыхательных путей вирусами группы острых респираторных вирусных инфекций (ОРВИ), а также грибковыми и бактериальными возбудителями. Воспаление может распространяться на нижние отделы дыхательных путей и поражать бронхи, бронхиолы и легочную ткань. Постановка диагноза должна учитывать эпидемическую обстановку, клинические особенности течения заболевания, а также лабораторное определение возбудителя. В рекомендациях IDSA указана необходимость расширения применения современной молекулярной диагностики, которая позволяет получить точные результаты в течение 15-60 мин и избежать ложноотрицательного результата, В т. ч. ее применение среди госпитализированных пациентов с респираторными симптомами. В рекомендациях отмечается, что пациенты, которые госпитализируются с симптомами гриппа и у которых имеется повышенный риск осложнений, должны быть протестированы и лечение должно быть начато немедленно. Противовирусные препараты должны быть назначены пациентам с высоким риском осложнений от гриппа, даже если с момента начала болезни прошло больше 2 дней; при госпитализации пациента с подозрением на грипп, у которого имеется высокий риск осложнений, необходимо начать противовирусную терапию, не дожидаясь результатов молекулярного тестирования.

Среди осложнений, обусловленных вирусной инфекцией, выделяют ринит, отит, синусит, фарингит, тонзиллит, ларингит, трахеит, бронхит, бронхиолит, пневмонию. Воздействие вируса гриппа может приводить к жизнеугрожающим осложнениям: инфекционно-токсическому шоку, геморрагическому шоку, рабдомиолизу. В группу риска по тяжелому течению гриппа входят больные с сахарным диабетом, артериальной гипертонией, ожире- нием, алкоголизмом и другими хроническими заболеваниями, а также беременные, пожилые люди и дети до 1 года [2, 3]. Грипп способен обострять течение других сопутствующих заболеваний, что чрезвычайно опасно для людей с хронической патологией сердечно-сосудистой системы, органов дыхания, эндокринной системы, центральной нервной системы и др.

Бактериальное поражение дыхательных путей может быть первичным, также бактериальная флора может быть следствием присоединения к вирусной инфекции и приводить к развитию вторичной бактериальной пневмонии (4\%), бронхита, бактериального поражения верхних дыхательных путей: гнойного фарингита, ринита, гайморита, тонзиллита, а также орбитальных осложнений (флегмоны орбиты, периостит), отитов, внутричерепных осложнений.

Профилактикой осложненного течения ОРЗ является своевременное назначение лечения. Решение о месте проведения лечения пациента - амбулаторно или в стационаре - принимается с учетом тяжести течения заболевания и риска развития осложнений ${ }^{1}$ [4].

\section{ГОСПИТАЛИЗАЦИЯ ПАЦИЕНТОВ С ОРЗ}

Разработанные рекомендации по госпитализации пациентов с гриппом могут быть применены на практике и к другим ОРЗ:

1. Тяжелое состояние больного, обусловленное интоксикацией (гипертермия, геморрагический синдром, спутанность сознания, менингизм, бред, гипоксия, нарушение ритма сердечных сокращений, бледность кожи, уменьшение диуреза, тошнота, рвота).

2. Осложненные формы гриппа (наличие симптомов дыхательной недостаточности и/или отека легких, кровохарканье, бронхообструктивный синдром, острый отечный ларингит, пневмония, острое воспаление придаточных пазух носа).

3. Больные из группы риска неблагоприятного развития болезни:

- дети младше 2 лет;

- беременные на любом сроке беременности;

- лица с хроническими заболеваниями легких (бронхиальная астма, ХОБЛ);

- лица с хроническими заболеваниями сердечно-сосудистой системы (пороки, ИБС с признаками сердечной недостаточности);

- лица с нарушениями обмена веществ (сахарный диабет, ожирение 2-3 степени);

- лица с хронической болезнью почек, хронической болезнью печени, с определенными неврологическими состояниями (включая нейромускульные, нейрокогнитивные нарушения, эпилепсию), гемоглобинопатиями или угнетенным иммунным состоянием либо по причине первичных иммуносупрессивных состояний, таких как

${ }^{1}$ Никифоров В.В., Колобухина Л.В., Суранова Т.Г. и др. Грипп и острые респираторные вирусные инфекции: современная рациональная этиотропная и патогенетическая терапия. Алгоритмы оказания медицинской помощи больным. Метод. рекомендации. М.: Спецкнига, 2018. 24 c. 
ВИЧ-инфекция, либо в связи со вторичными иммунодефицитными состояниями вследствие приема иммуносупрессорных медикаментов или злокачественных новообразований;

- дети, получавшие аспирин для лечения хронического заболевания;

лица в возрасте 65 лет и старше.

Существуют эпидемиологические показания для госпитализации: больные из организованных, закрытых коллективов: военнослужащие, учащиеся интернатов, студенты, проживающие в общежитиях, при невозможности их изоляции от окружающих по месту жительства. Поводом для госпитализации может являться невозможность постоянного медицинского наблюдения.

\section{АМБУЛАТОРНОЕ ВЕДЕНИЕ ПАЦИЕНТОВ С ОРЗ}

Если больной остается дома, то его местопребывание становится первичным очагом инфекции и лечащему врачу необходимо организовать проведение противоэпидемических мероприятий, а также экстренную профилактику лиц, находящихся в тесном контакте с больным. Доступ к больному ограничивается, а люди, обеспечивающие уход, должны применять с целью защиты марлевые респираторы. В помещении должна проводиться дезинфекция предметов быта и обстановки. Ежедневно проводят влажную уборку с применением 0,5\% раствора хлорамина, рекомендуется 2-3 раза в день проветривание помещений.

Немедикаментозные вмешательства кроме соблюдения гигиенических мероприятий включают режим и диету. В течение всего лихорадочного периода и интоксикации больному необходимо соблюдение постельного режима. Через 3 дня после нормализации температуры тела и исчезновения интоксикации разрешается полупостельный режим. Для уменьшения интоксикации показано введение достаточного количества жидкости (15001700 мл) и витаминов. В первые дни болезни калорийность рациона снижают до 1600-1800 ккал. Назначают частый прием пищи (6-7 р/сут), преимущественно в жидком и хорошо измельченном виде. Положительное значение имеет одновременное насыщение диеты продуктами, богатыми витаминами С и Р (черноплодная рябина, шиповник, черная смородина, лимоны и др.). Возможно назначение витаминов, обладающих антиоксидантным эффектом: рутозида, дигидрокверцетина, витаминов Е и С и др.

Успех терапии во многом обусловлен наиболее ранним ее началом. Терапия ОРЗ должна быть комплексной, адекватной этиологии и тяжести течения заболевания и направленной на все звенья патогенеза. Тактика этиотропной терапии обусловлена возбудителем заболевания и предусматривает либо противовирусную, либо антибактериальную терапию.

Основной задачей терапии гриппа и других ОРВИ является подавление репликации вирусов на ранних сроках болезни. Для лечения гриппа используют этиотропные препараты - ингибиторы нейраминидазы осельтами- вир и занамивир, эффективные в отношении большинства вирусов гриппа, включая пандемический. В России широкое применение получил препарат осельтамивир, рекомендованный для лечения гриппа у взрослых и детей в возрасте старше 1 года. Применение занамивира, который вводится ингаляционно, несколько ограничено в связи с возможностью развития бронхоспазма, особенно у больных бронхиальной астмой и ХОБЛ, а также с невозможностью применения у детей до 5 лет, у больных, находящихся на ИВЛ.

В качестве противовирусных препаратов в России также применяются умифеновир и риамиловир. Вирусы гриппа, циркулирующие на территории Российской Федерации, - A(H1N1)pdm09, A(H3N2) и B, чувствительны также и к имидазолилэтанамиду пентандиовой кислоты [3]. Эффективность всех противовирусных препаратов напрямую зависит от их раннего назначения. Из недостатков препаратов следует отметить развитие резистентности. По данным различных авторов, частота резистентности клинических штаммов вирусов гриппа к препаратам группы ингибиторов нейраминидазы составляет 2-4\%. Кроме того, имеющиеся противогриппозные препараты, к сожалению, не обладают противовирусным эффектом в отношении других ОРВИ.

В терапии ОРВИ нашли применение препараты С двойным механизмом действия: противовирусной активностью и иммуномодулирующими свойствами - интерфероны и индукторы интерферонов [5].

К возбудителям ОРЗ бактериальной природы относятся микоплазмы, хламидии, пневмококки, гемофильная палочка, стрептококки, реже - грамотрицательная флора. Нередко на фоне вирусного поражения респираторного тракта, сопряженного с иммунодефицитом, а также при наличии факторов риска (переохлаждение, большие физические нагрузки, эмоциональное напряжение и др.) происходит активация собственной условно-патогенной флоры и, как следствие, развитие осложнений в виде бронхитов и пневмоний. В 80-90\% случаев развиваются пневмонии. В этиологии пневмоний доминирует пневмококковая флора.

\section{ОСЛОЖНЕНИЯ ОРЗ}

Признаками развившегося осложнения являются: отсутствие положительной динамики в течении заболевания, лихорадка более 5 дней без тенденции к снижению, вторая волна лихорадки, длительно сохраняющиеся или нарастающие симптомы интоксикации, присоединение потливости, изменение характера кашля, возвращение респираторных симптомов, присоединение новых симптомов, характерных для риносинусита, бронхита, пневмонии и других заболеваний [5]. Показаниями для проведения системной антибактериальной терапии при ОРЗ являются: острый стрептококковый тонзиллит, гнойный риносинусит, гнойный средний отит, ларингит с явлениями стеноза гортани 3 степени, острый гнойный бронхит, бактериальная пневмония, паратонзиллярный абсцесс. В 25\% случаев острого бронхита и в 20\% случа- 
ев пневмонии этиологическим фактором являются хламидии и микоплазмы. Эти возбудители являются частой причиной развития синуситов, фарингита, отита у детей, особенно младшей возрастной группы. Лечение заболеваний, обусловленных внутриклеточными возбудителями, проводится антибактериальными препаратами, легко проникающими внутрь клетки и способными создавать там высокую концентрацию.Антибактериальными препаратами первого ряда, применяемыми при респираторной хламидийной и микоплазменной инфекции, являются макролиды. Перед началом антибактериальной терапии при ОРЗ необходим бактериологический анализ для определения возбудителя и его чувствительности к антибиотикам.

При ОРЗ бактериальной этиологии широко используется местная антибактериальная терапия. Лекарственный препарат в виде спрея вводится локально в нос или зев. При этом минимизируется системное воздействие, включая риски побочных реакций, подавление нормальной микрофлоры, развитие антибиотикорезистентности.

При лечении ОРЗ возможно использование физических методов снижения температуры, проведение санации верхних дыхательных путей (носовых ходов), физиотерапии.

Подход к снижению температуры должен быть дифференцированным. Температурная реакция организма при ОРВИ является защитной, она стимулирует выработку эндогенного интерферона, активизируя иммунную систему, препятствует размножению вируса, способствует их элиминации и гибели. В то же время повышение температуры свыше $39{ }^{\circ} \mathrm{C}$ может приводить к тяжелым осложнениям со стороны нервной и сердечно-сосудистой систем, что связано с повышением потребления кислорода, усилением потери жидкости, дополнительной нагрузкой на легкие и сердце. Снижение температуры жаропонижающими средствами не должно иметь целью нормализацию температуры, обычно достаточно снизить ее на 1-1,5 ${ }^{\circ} \mathrm{C}$. Обоснованным считается применение жаропонижающих препаратов при температуре выше $38,5{ }^{\circ} \mathrm{C}$, рекомендовано применение препаратов на основе парацетамола.

Часто пациент с гриппом и другими ОРВИ для облегчения симптомов нуждается в дополнительной симптоматической терапии. Одним из симптомов, влияющих на качество жизни пациента с гриппом, является ринорея. При ринорее используют местные сосудосуживающие препараты, предпочтительно в форме спрея (ксилометазолин, оксиметазолин). В то же время частое и длительное применение этих препаратов может приводить к развитию атрофических изменений слизистой носа и другим осложнениям.

\section{СИМПТОМ КАШЛЯ}

Одним из самых распространенных симптомов при заболевании дыхательной системы является кашель, который наблюдается при ОРВИ, бронхите, бронхиаль- ной астме, пневмонии, плеврите и др. Если рассматривать кашель с точки зрения эпидемиологии, то он является путем передачи инфекционных заболеваний. При кашле с потоком воздуха при респираторной инфекции происходит выброс бактерий и вирусов в радиусе 2-3 м с высокой концентрацией патогенной флоры. Поэтому при контакте с кашляющим человеком с инфекционным заболеванием требуется соблюдение определенных гигиенических правил поведения. Физиологически кашель является защитным рефлексом, направленным на защиту дыхательных путей от инородных частиц. В то же время кашель - симптом заболеваний, а интенсивный кашель даже может приводить к развитию осложнений. У кашляющего больного страдает качество жизни (вплоть до развития депрессии). Это обусловлено нарушением сна, утомлением, негативной реакцией окружающих, связанной с опасением, что кашляющий человек может являться источником инфекции. Снижение качества жизни кашляющего человека сопоставимо с качеством жизни пациента с ХОБЛ или онкологическим заболеванием.

По характеру выделения мокроты кашель разделяют на продуктивный и непродуктивный. Основные причины непродуктивного кашля: заболевания верхних дыхательных путей (риниты, синуситы и др.), воздействие аллергенов, вдыхание раздражающих веществ (дым, пыль), попадание в дыхательные пути инородного тела, бронхиальная астма, ГЭРБ, сердечная астма, перикардит, наружный отит. Продуктивный кашель встречается при хроническом бронхите, бронхоэктатической болезни, пневмонии, бронхиальной астме, раке легкого, абсцессе легкого, туберкулезе легких и др. В случае продуктивного кашля необходимо проведение исследования мокроты. Оцениваются запах, цвет, объем мокроты, разделение на слои, что предварительно может позволить определить заболевание. Слизистая мокрота чаще наблюдается при ОРВИ, гнойная мокрота характерна для бактериальных инфекций дыхательных путей и имеет желтый или зеленоватый цвет. Большое количество мокроты, как правило, выделяется при нагноительных заболеваниях: гангрене легких, абсцессе, бронхоэктатической болезни. При наличии продуктивной мокроты обязательно проводится бактериологическое исследование: микроскопия мазков, окрашенных по Граму и Цилю - Нильсену, посев и определение чувствительности бактерий к антибиотикам.

Американской коллегией специалистов торакальной медицины предложен алгоритм диагностики острого кашля [6]. Согласно рекомендациям наиболее частыми причинами острого кашля являются респираторные инфекции с вирусным возбудителем. Вирусная инфекция может осложняться пневмонией или являться причиной обострения хронических заболеваний, таких как астма и ХОБЛ (рис. 1). Особое внимание уделяется жизнеугрожающим состояниям, таким как туберкулез и рак легкого. Диагноз туберкулеза требует исключения в группах высокого риска, даже если рентгенограммы в норме. 
- Рисунок 1. Алгоритм поиска причин острого кашля у взрослых

Figure 1. Algorithm of searching for causes of acute cough in adults

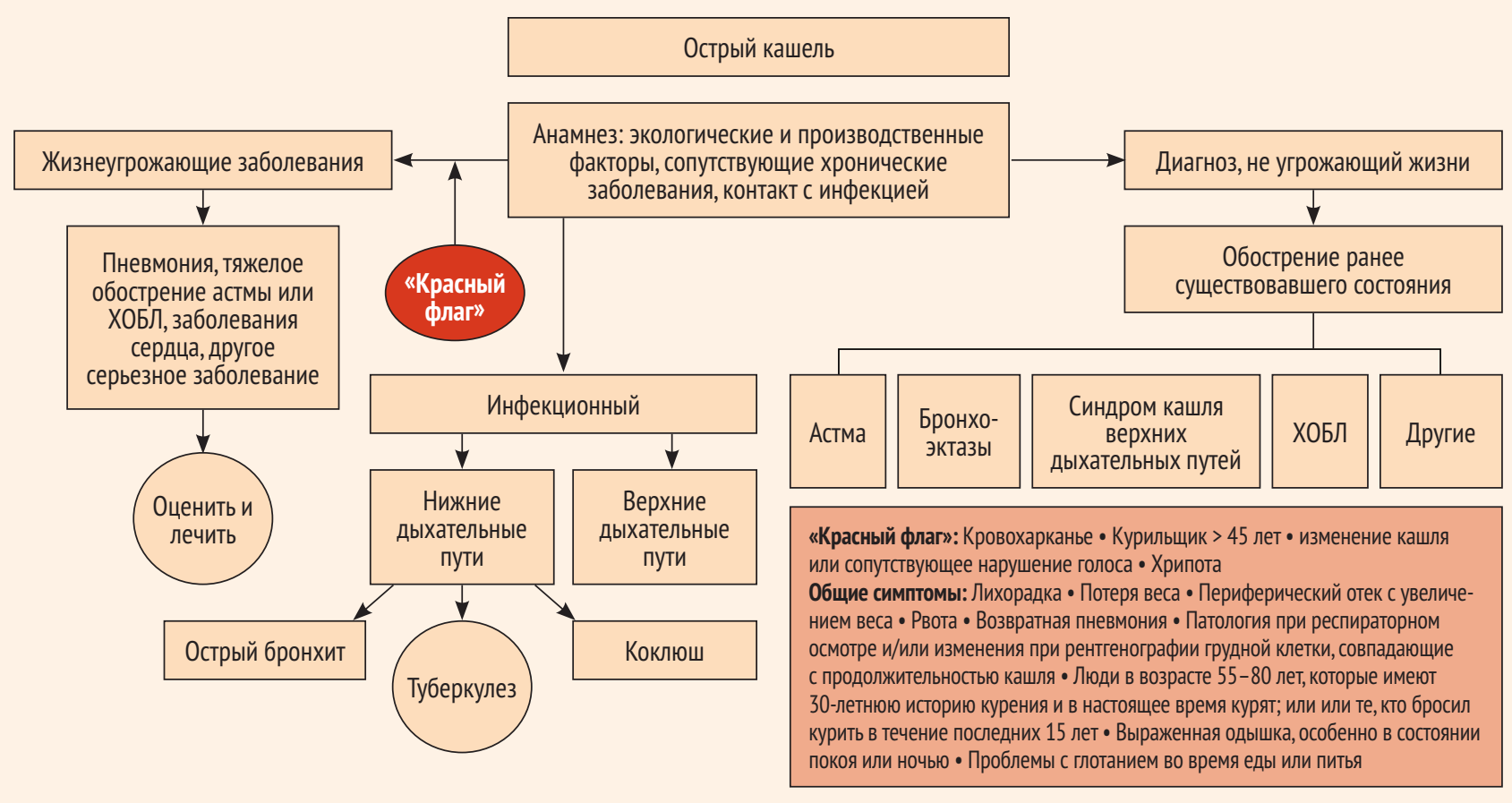

\section{ЛЕЧЕНИЕ КАШЛЯ}

Препараты от кашля, подавляющие кашлевой рефлекс, разделяют по механизму: центрального действия (опиоидные и неопиоидные) и периферического действия. Препараты центрального действия подавляют кашлевой центр в центральной нервной системе (продолговатом мозге). В основу опиоидных препаратов входит кодеин или подобные ему вещества. Неопиоидные противокашлевые препараты центрального действия подавляют только кашлевой центр, не вызывают привыкания, не изменяют двигательную активность желудочно-кишечного тракта. К ним относятся препараты на основе бута- мирата. Противокашлевые препараты периферического действия оказывают влияние на слизистую оболочку дыхательных путей, снижая ее раздражение, расширяют гладкие мышцы в стенках бронхов, уменьшая бронхоспазм, обладают противовоспалительной активностью.

При продуктивном кашле подходы к терапии меняются. При наличии мокроты подавление кашлевого рефлекса не проводится во избежание нарушения эвакуации мокроты из бронхов. Назначаются секретолитические и секретомоторные препараты, улучшающие эвакуацию мокроты (рис. 2).

Одним из препаратов, обладающих отхаркивающим, муколитическим и спазмолитическим действием, являет-

Рисунок 2. Препараты, применяемые для лечения продуктивного кашля

- Figure 2. Cough medicines used for the treatment of productive cough

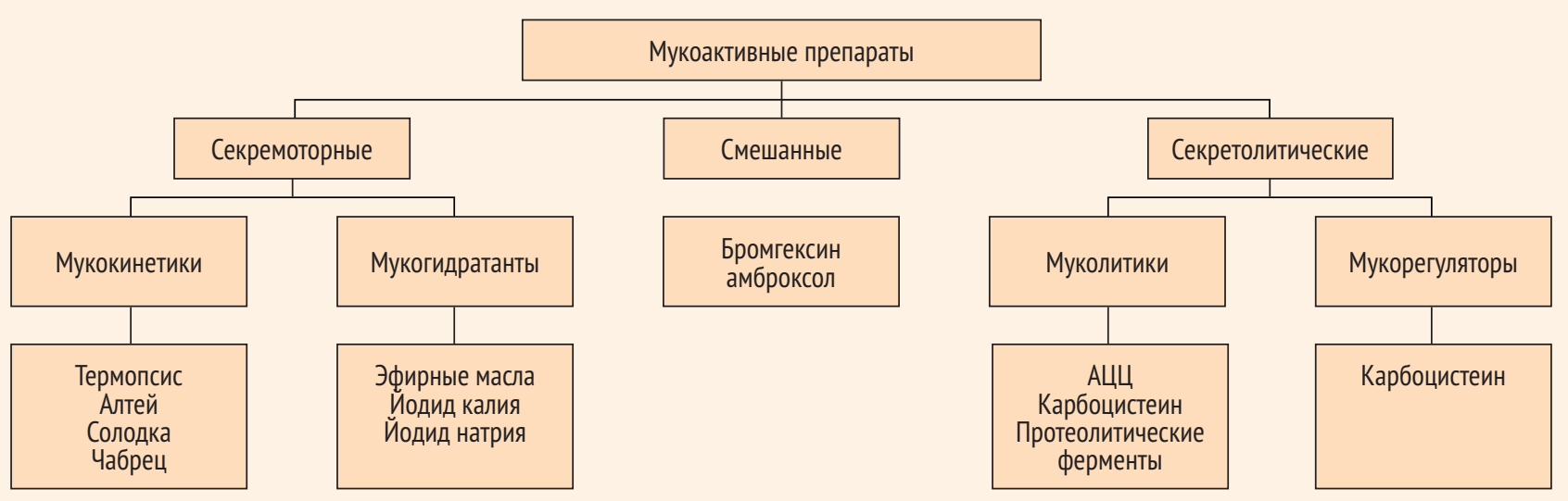


ся сироп Геделикс растительного происхождения на основе листьев плюща. Препарат рекомендуется принимать после еды 3-4 р/сут, детям до года - 1 р/сут, курс лечения составляет не менее 7 дней, после прекращения кашля сироп рекомендовано принимать еще 2-3 дня. Лекарственная форма в виде сиропа удобна для детей и взрослых. Дозировка препарата определяется возрастом пациента, имеющаяся в комплекте мерная ложечка на 5 мл позволяет отмерить дозу препарата. Геделикс ${ }^{\circledR}$ сироп не рекомендуется применять при беременности и в период грудного вскармливания.

Плющ (Hedera helix) является уникальным целебным растением. Многочисленные изображения на религиозных и бытовых предметах, монетах свидетельствуют о том, что в Древнем Египте, Греции и Риме плющ был культовым растением. В Древнем мире плющ считали символом бессмертия. Упоминание о его применении в лечебных целях относится к античным временам, плющ упоминается в трудах Авиценны и европейских средневековых травниках. Листья плюща применяли в виде отвара при родовой слабости и аменорее; при ранах и ожогах использовали настои листьев плюща в вине и мази на основе воска.

Основными биологически активными веществами, обусловливающими фармакологическую активность листьев и лекарственных средств из плюща, являются тритерпеновые сапонины, а также флавоноиды и гликозиды, дубильные вещества, стероиды, йод, каротин, витамины В, С и Е и другие биологические активные вещества. За счет высокомолекулярных углеводов растение обладает сорбционным эффектом. Сапониновые гликозиды оказывают антибактериальное и противофунгальное действие, способствуют устранению воспалений дыхательной системы, эффективно расслабляют бронхиальную мускулатуру, усиливают секрецию бронхиальных желез, разжижают и выводят мокроту, стимулируют откашливание, а также восстанавливают нормальное дыхание. Секретолитическое действие плюща также связано с содержащимся в сырье алкалоидом эметином, который усиливает секрецию слизи из альвеол. При этом действующие вещества не оказывают влияния на центр регуляции дыхания. Различные формы на основе плюща оказывают жаропонижающее и общеукрепляющее действие, а также обладают частичным гипотензивным эффектом. Муколитические и бронхорасширяющие эффекты плюща используются: при воспалительных процессах в бронхах;

- для восстановления в послеоперационном периоде;

- при бронхиальной астме;

- при воспалении легких;

при заболеваниях, сопровождающихся сухим лающим кашлем и трудноотделяемой мокротой;

для лечения коклюша;

д для лечения туберкулеза легких.

Также эффекты плюща успешно используются при воспалении среднего уха, хроническом насморке, рахите, аменорее, заболеваниях печени и желчного пузыря, язвенной болезни желудка и двенадцатиперстной кишки, подагре, ревматизме. Наружно применяют при лечении кожных заболеваний. Если раньше растение длительное время применяли исключительно в народной медицине, то сегодня экстракт плюща используется в составе многих медицинских средств.

Плющ обыкновенный редко вызывает аллергическую реакцию, разрешается детям и беременным. Однако детям до 1 года, беременным, кормящим и людям, склонным к аллергическим реакциям, лечение рекомендовано проводить под контролем врача. Противопоказания к применению: заболевания печени, алкоголизм, черепномозговая травма, заболевания ЦНС. Препараты на основе плюща не назначаются одновременно со средствами, подавляющими кашель. Среди негативных реакций отмечены: зуд и покраснение кожного покрова, отечность, нарушение нормального дыхания, рвотные позывы и тошнота, расстройства стула, нарушения ЦНС.

\section{ЗАКЛЮЧЕНИЕ}

Препарат Геделикс обладает всеми лекарственными эффектами, свойственными препаратам на основе плюща, и в то же время является готовой формой, удобной в применении, зарекомендовавшей свою эффективность в клинических исследованиях и в практическом применении. Однако необходимо помнить, что растительные препараты на основе плюща, в т. ч. Геделикс, относятся к симптоматическим средствам, поэтому параллельно врачом должно быть назначено этиотропное лечение основного заболевания.

Поступила / Received 28.08.2019 Отрецензирована / Review 17.09.2019 Принята в печать / Accepted 20.09.2019

\section{- Список литературы}

1. Брико Н.И., Салтыкова Т.С., Герасимов А.Н., Суранова Т.Г., Поздняков А.А., Жигарловский Б.А. Клинико-эпидемиологическая характеристика гриппа в 2015-2016 и 2016-2017 гг. Эпидемиология и инфекционные болезни. Актуальные вопросы. 2017;(4):4-13. Режим доступа: https://elibrary.ru/item.asp?id=29970301.

2. Суранова Т.Г., Поздняков А.А., Полежаева Н.А. Результаты мониторинга случаев смерти от гриппа в сезоны 2015-2016 и 2016-2017 гг. Инфекция и иммунитет. 2017;(5):74. Режим доступа: https://elibrary.ru/item. asp?id=35379584.
3. Брико Н.И., Салтыкова Т.С., Герасимов А.Н., Поздняков А.А., Брусина Е.Б., Зуева Л.П., Любимова А.В., Голубкова А.А., Суранова Т.Г., Толоконникова Т.В., Туркутюков В.Б., Шумилов В.И., Калинкина В.А., Ковалишена О.В., Белоцерковцова Л.Д. Отношение беременных и медицинских работников к вакцинации против гриппа. Эпидемиология и вакцинопрофилактика. 2017;16(1):55-61. doi: 10.31631/2073-3046-2017-16-1-55-61.

4. Международная ассоциация специалистов в области инфекций. Грипn у взрослых Клинические рекомендации. 2017. 57 с. Режим доступа: http://kokb45.ru/wp-content/ uploads/2018/06/Gripp-u-vzroslyh.pdf.

5. Национальное научное общество инфекционистов. Острые респираторные вирусные инфекции у взрослых. Клинические рекомендации. 2014. 69 с. Режим доступа: http://nnoi. ru/uploads/files/protokoly/ORVI_adult.pdf.

6. Irwin R.S., French C.L., Chang A.B., Altman K.W.; CHEST Expert Cough Panel. Classification of Cough as a Symptom in Adults and Management Algorithms CHEST Guideline and Expert Panel Report. Chest. 2018;153(1):196209. doi: 10.1016/j.chest.2017.10.016. 


\section{References}

1. Briko N.I., Saltykova T.S., Gerasimov A.N., Suranova T.G., Pozdnyakov A.A.,

Zhigarlovsky B.A. Clinical and epidemiological characteristics of influenza in 2015-2016 and 2016-2017. Ehpidemiologiya i infektsionnye bolezni. Aktual'nye voprosy = Epidemiology and Infectious Diseases. Current Items. 2017;(4):4-13. (In Russ.) Available at: https:// elibrary.ru/item.asp?id=29970301.

2. Suranova T.G., Pozdnyakov A.A., Polezhayeva N.A. Results of monitoring of deaths from influenza in the seasons 2015-2016 and 2016-2017. Infektsiya i immunitet $=$ Russian Journal of Infection and Immunity. 2017;(5):74. (In Russ.) Available at: https://elibrary.ru/item.asp?id=35379584.
3. Briko N.I., Saltykova T.S., Gerasimov A.N., Pozdnyakov A.A., Brusina E.B., Zueva L.P. Lyubimova A.V., Golubkova A.A., Suranova T.G., Tolokonnikova T.V., Turkutyukov V.B., Shumilov V.I., Kalinkina V.A., Kovalishena O.V., Belotserkovtsova L.D. The Attitude of Pregnant Women and Health Workers for Influenza Vaccination. Ehpidemiologiya i vaktsinoprofilaktika = Epidemiology and Vaccinal Prevention. 2017;16(1):55-61. (In Russ.) doi: 10.31631/2073-3046-2017-16-1-55-61.

4. International Society for Infectious Diseases. Gripp u vzroslykh. Klinicheskiye rekomendatsii = Influenza in adults. Clinical guidelines. 2017. 57 c. (In Russ.) Available at: http://kokb45.ru/
wp-content/uploads/2018/06/Gripp-uvzroslyh.pdf.

5. National Infectionist Scientific Society. Ostryye respiratornyye virusnyye infektsii u vzroslykh. Klinicheskiye rekomendatsii $=$ Acute respiratory viral infections in adults. Clinical guidelines. 2014. 69 c. (In Russ.) Available at: http://nnoi. ru/uploads/files/protokoly/ORVI_adult.pdf.

6. Irwin R.S., French C.L., Chang A.B., Altman K..W.; CHEST Expert Cough Panel. Classification of Cough as a Symptom in Adults and Management Algorithms CHEST Guideline and Expert Panel Report. Chest. 2018;153(1):196209. doi: $10.1016 /$ j.chest.2017.10.016

\section{Информация об авторе:}

Орлова Наталья Васильевна, д.м.н., доцент, профессор кафедры факультетской терапии педиатрического факультета, Федеральное государственное бюджетное образовательное учреждение высшего образования «Российский национальный исследовательский медицинский университет имени Н.И. Пирогова» Министерства здравоохранения Российской Федерации; 117997, Россия, Москва, ул. Островитянова, д. 1; e-mail:vrach315@yandex.ru

\section{Information about the author:}

Natal'ya V. Orlova, Dr. of Sci. (Med), Associate Professor, Professor of the Department of Paediatric Therapy, Federal State Budgetary Educational Institution of Higher Education «Pirogov Russian National Research Medical University» of the Ministry of Health of the Russian Federation; 1 , Ostrovityanova St., Moscow, 117997, Russia; e-mail: vrach315@yandex.ru 